\title{
EFFECTIVENESS MONTASE AS TUBERCULOSIS AWARENESS PROGRAM AND ASSOCIATED CHANGES IN KNOWLEDGE LEVELS OF THE FAMILIES
}

Linda Widyarani ${ }^{1 *}$, Cecilya Kustanti ${ }^{1}$

Afiliasi

1. Sekolah Tinggi Ilmu Kesehatan Notokusumo Yogyakarta

\section{Dikirim 12 okt 2020}

Direvisi 9 nov 2020

Di terima 11 nov 2020

Dipublikasikan 30 november 2020

Korespondensi

Email :

lindawidyarani@gmail.com

\begin{abstract}
ABSTRAK
Keberhasilan pengendalian TB sangat dipengaruhi oleh peran dan dukungan keluarga. Keluarga yang tidak peduli, tidak mendukung program pengobatan, cenderung acuh, tidak melakukan upaya pencegahan penularan dalam perawatan anggota keluarga dengan TB, serta pemberian stigma negatif terhadap penyakit TB memberikan dampak negatif bagi keberhasilan pengendalian TB. Salah satu upaya membangun dan meningkatkan peran keluarga dalam pengendalian TB yaitu memberikan edukasi tentang pencegahan penularan dalam perawatan anggota keluarga dengan TB dengan metode MONTASE. Penelitian ini bertujuan untuk mengetahui efektifitas metode pembelajaran MONTASE terhadap peningkatan kemampuan responden dalam mempraktikkan upaya pengendalian dan pencegahan penularan dalam perawatan anggota keluarga dengan TB. Penelitian ini menggunakan metode quasi eksperiment dengan one group pre-post test design, jumlah responden sebanyak 31 orang didapatkan dengan teknik purposive sampling. Intervensi yang digunakan adalah penerapan seni 3M yaitu melipat, menggunting dan menempelkan gambar diatas kertas yang membentuk cerita bergambar. Pada penelitian ini diperoleh ratarata nilai pretest adalah $48,39 \pm 5,536$ dan nilai posttest adalah $73,23 \pm 11,729$, dengan nilai p-value sebesar 0,000 yang artinya terdapat perbedaan yang signifikan antara pengetahuan sebelum dan sesudah intervensi. Oleh karena itu, strategi pemberian edukasi dengan metode pembelajaran MONTASE perlu diintegrasikan dalam program promotif.
\end{abstract}

Kata kunci : Tuberculosis , MONTASE, pencegahan penularan

\begin{abstract}
The success of TB control is strongly influenced by the role and support of the family. Families who do not care, do not support treatment programs, tend to be ignorant, do not make efforts to prevent transmission in the care of family members with TB, and give negative stigma against TB disease has a negative impact on the success of TB control. One of the efforts to build and increase the role of the family in TB control is to provide education on prevention of transmission in the care of family members with TB using the Montage method. This study aims to determine the effectiveness of the montage learning method in increasing knowledge about control and prevention of transmission in the care of family members with TB. This study used a quasi-experimental method with one group pre-post test design. We obtain 31 respondents with a purposive sampling technique. The intervention used is application of $3 \mathrm{M}$ art, namely folding, cutting and pasting pictures on paper that form pictorial stories. In this study, the average pretest value was $48.39 \pm 5.536$ and the posttest value was $73.23 \pm 11.729$, with a p-value of 0.000 , which means that there was a significant difference between the knowledge before and after the intervention. Therefore, the strategy of providing education with the montage learning method needs to be integrated into the promotional program.
\end{abstract}

Keyword : Tuberculosis, MONTAGE, prevention of transmission

Sitasi jurnal :

Widyarani L, Kustanti C. 2020 Effectiveness Montase As Tuberculosis Awareness Program And Associated Changes In Knowledge Levels Of The Families. Jurnal Ilmu Keperawatan 8 (2): 102-107. Doi: 10.21776/ub.jik.2020.008.02.6 


\section{PENDAHULUAN}

Tuberkulosis masih menjadi peringkat ke-2 penyebab kematian di Indonesia (Kemenkes RI, 2016). Indonesia menempati peringkat ke- 2 dengan pasien $\mathrm{TB}$ terbanyak di dunia (WHO, 2018). Angka kesembuhan TB di Indonesia ditargetkan mencapai 85\%, hal ini belum dicapai secara optimal di D.I. Yogyakarta (Kemenkes., 2017). Kabupaten Bantul memiliki angka kesembuhan TB yaitu 65\%, prosentase ini lebih rendah dibandingkan Sleman $(91,64 \%)$, Gunung Kidul (83,87\%), Kota Yogyakarta $(77,64 \%)$ dan Kulonprogo (80\%) (Kemenkes, 2018).

Salah satu wilayah di Kabupaten Bantul yaitu Desa Wukirsari. Desa Wukirsari merupakan salah satu daerah binaan Puskesmas Imogiri I, berdasarkan studi pendahuluan yang telah dilakukan dengan Koordinator P2M Puskesmas Imogiri I dan Kepala Puskesmas Imogiri I, menyatakan bahwa sampai dengan bulan Mei Tahun 2020, terlaporkan terdapat 19 orang pasien TB, belum termasuk missing case, bahkan ada yang saat ini sedang hamil sehingga merasa takut dan berhenti minum obat.

Sebagian besar penderita TB tidak menggunakan masker pada saat melakukan kegiatan sehari-hari dengan alasan kesulitan bernafas. Penderita masih makan bersama atau menyuapi anak dengan alat makan yang sama secara bergantian, dan membuang dahak sembarangan. Sebagian besar masih menganggap penyakit TB merupakan penyakit keturunan sehingga berdampak pada munculnya sikap pasrah yang ditunjukkan dengan kurang giatnya melakukan upaya pengobatan, keluarga penderita juga acuh dan tidak peduli terhadap pengobatan yang dijalani serta keluarga juga tidak paham tentang pencegahan penularan TB. Sebagian besar juga berpersepsi bahwa penyakit TB merupakan penyakit batuk biasa dan tidak perlu penanganan yang serius. Penyuluhan bertema "Lawan TB dengan Gerduda" sudah pernah diberikan oleh Puskesmas Imogiri I dengan metode konvensional, akan tetapi belum mampu memberikan pemahaman dan kesadaran kepada warga Desa Wukirsari.

Keberhasilan pengendalian TB sangat dipengaruhi oleh peran dan dukungan keluarga. Keluarga yang tidak peduli, tidak mendukung program pengobatan, cenderung acuh, tidak melakukan upaya pencegahan penularan dalam perawatan anggota keluarga dengan
TB, serta pemberian stigma negatif terhadap penyakit TB memberikan dampak negatif bagi keberhasilan pengendalian TB (Widiastuti., 2019). Salah satu upaya membangun dan meningkatkan peran keluarga dalam pengendalian TB yaitu memberikan pembelajaran tentang pencegahan penularan dalam perawatan anggota keluarga dengan TB dengan metode MONTASE. Metode MONTASE adalah penerapan seni 3M yaitu melipat, menggunting dan menempelkan gambar diatas kertas, yang membentuk cerita bergambar, yang lebih aktif, kreatif, inovatif, efektif dan menyenangkan daripada metode konvensional (Mulyatiningsih., 2017).

Berdasarkan latar belakang tersebut, permasalahan yang diteliti adalah bagaimana pengaruh metode MONTASE terhadap kemampuan keluarga dalam mencegah penularan dalam perawatan anggota keluarga dengan TB. Tujuan penelitian ini adalah untuk mengetahui kemampuan anggota keluarga tentang tindakan yang dilakukan dalam pengendalian dan pencegahan penularan dalam perawatan anggota keluarga dengan TB sebelum dan setelah diberikan intervensi.

\section{METODE}

Penelitian ini menggunakan metode quasi eksperiment dengan one group pre-post test design. Penelitian ini dilaksanakan di Desa Wukirsari sebagai daerah binaan Puskesmas Imogiri I, Kabupaten Bantul, Daerah Istimewa Yogyakarta. Populasi pada penelitian ini adalah seluruh anggota keluarga yang bertempat tinggal serumah dan bertempat tinggal dekat dengan penderita TB di wilayah Desa Wukirsari.

Adapun kriteria inklusi pada penelitian ini yaitu keluarga yang tinggal serumah dan bertempat tinggal dekat dengan penderita TB serta bersedia menjadi responden, sedangkan kriteria eksklusinya adalah tidak hadir pada saat dilakukan intervensi. Jumlah responden sebanyak 31 orang. Teknik sampling yang digunakan adalah purposive sampling. Penelitian ini dilakukan pada bulan Agustus-September 2020. Pada penelitian ini, intervensi yang diberikan pada responden adalah penerapan seni 3M yaitu melipat, menggunting dan menempelkan gambar diatas kertas, yang membentuk cerita bergambar. Penelitian ini menggunakan media seperti kertas HVS ukuran A3, kertas origami, lem perekat, gunting, pensil warna dan spidol. 
Analisis data dilakukan menggunaan uji paired $t$ test dengan tingkat kemaknaan $\alpha \leq 0,05$. Pengambilan data dilakukan dengan metode observasi. Instrumen pengambilan data menggunakan lembar checklist dengan 10 item penilaian mencakup tindakantindakan yang dapat dilakukan oleh responden sebagai upaya pengendalian dan pencegahan penularan dalam perawatan anggota keluarga dengan TB. Lembar checklist tersebut sudah dilakukan uji validitas dan reabilitas. Uji validitas dan reabilitas ini dilakukan dengan bantuan software SPSS. Hasil uji validitas valid dengan $p$ value $<0,05$ dan person correlation bernilai positif. Hasil uji reabilitas dinyatakan reliable karena nilai cronbachs alpha $(\alpha)$ yaitu 0,963 .

Pada tahap awal, responden mempraktikkan tindakan-tindakan yang dapat dilakukan sebagai upaya pengendalian dan pencegahan penularan dalam perawatan anggota keluarga dengan TB sebelum diberikan intervensi MONTASE (pretest), kemudian responden diminta memilih gambar yang sesuai dengan tindakan-tindakan yang tepat dilakukan sebagai upaya pengendalian dan pencegahan penularan dalam perawatan anggota keluarga dengan TB. Selanjutnya, responden diminta menggunting, melipat dan menempelkan gambar-gambar tersebut diatas kertas HVS ukuran A3 sehingga membentuk cerita bergambar. Pada tahap akhir, responden diminta kembali mempraktikkan tindakan-tindakan yang dapat dilakukan sebagai upaya pengendalian dan pencegahan penularan dalam perawatan anggota keluarga dengan TB setelah diberikan intervensi MONTASE (posttest).

\section{HASIL}

\section{A. Data Karakteristik Responden}

Tabel 1. Karakteristik Responden $(n=31)$

\begin{tabular}{|c|c|c|c|}
\hline No. & Status Demografi & $\begin{array}{c}\text { Frekuens } \\
\text { i } \\
\text { (n) }\end{array}$ & $\begin{array}{c}\text { Prosentase } \\
(\%)\end{array}$ \\
\hline 1 & Usia (Mean \pm SD) & \multicolumn{2}{|c|}{$43,17 \pm 6,690$} \\
\hline \multirow[t]{4}{*}{2} & Jenis Kelamin & & \\
\hline & Laki-laki & 21 & 67,7 \\
\hline & Perempuan & 10 & 32,3 \\
\hline & Total & 31 & 100 \\
\hline \multirow[t]{5}{*}{3} & Pendidikan Terak & & \\
\hline & $\mathrm{SD} / \mathrm{MI}$ & 10 & 32,3 \\
\hline & SMP/MTS & 13 & 41,9 \\
\hline & SMA/MA & 6 & 19,4 \\
\hline & Perguruan Tinggi & 2 & 6,5 \\
\hline \multirow[t]{6}{*}{4} & $\begin{array}{l}\text { Total } \\
\text { Pekeriaan }\end{array}$ & 31 & 100 \\
\hline & IRT/Tidak Bekeria & 17 & 54,8 \\
\hline & PNS/Guru & 2 & 6,5 \\
\hline & Wiraswasta & 4 & 12,9 \\
\hline & Swasta & 8 & 25,8 \\
\hline & Total & 31 & 100 \\
\hline \multirow[t]{4}{*}{5} & Mendapatkan Edu & & \\
\hline & Pernah & 6 & 19,4 \\
\hline & Tidak Pernah & 25 & 80,6 \\
\hline & Total & 31 & 100 \\
\hline
\end{tabular}

Sumber : Data primer yang diolah

Berdasarkan tabel 1, rata-rata usia responden adalah 43,17 $\pm 6,690$ tahun. Sebagian besar, berjenis kelamin laki-laki $(67,7 \%)$, berlatar pendidikan SMP $(41,9 \%)$, tidak bekerja $(54,8 \%)$ dan belum pernah mendapatkan edukasi sebelumnya tentang bagaimana pengendalian dan pencegahan penularan dalam perawatan anggota keluarga dengan TB $(80,6 \%)$. 


\section{B. KEMAMPUAN RESPONDEN DALAM MEMPRAKTIKKAN UPAYA PENGENDALIAN DAN PENCEGAHAN PENULARAN DALAM PERAWATAN ANGGOTA KELUARGA DENGAN TB}

Tabel 2. Distribusi Kemampuan Responden dalam mempraktikkan Upaya Pengendalian Dan Pencegahan Penularan Dalam Perawatan Anggota Keluarga Dengan TB Sebelum Dan Setelah Diberikan Intervensi $(n=31)$

\begin{tabular}{|c|c|c|c|c|c|c|}
\hline \multirow{4}{*}{$\begin{array}{c}\text { Dimensi Pengendalian Dan Pencegahan Penularan Dalam } \\
\text { Perawatan Anggota Keluarga Dengan TB }\end{array}$} & \multicolumn{6}{|c|}{ Total } \\
\hline & \multicolumn{3}{|c|}{ Pre } & \multicolumn{3}{|c|}{ Post } \\
\hline & $\mathbf{0}$ & 1 & 2 & $\mathbf{0}$ & 1 & 2 \\
\hline & n (\%) & n (\%) & n (\%) & n (\%) & n (\%) & n (\%) \\
\hline Menggunakan masker saat batuk/bersin & $2(6,3)$ & $\begin{array}{c}6 \\
(18,8)\end{array}$ & $\begin{array}{c}23 \\
(71,9)\end{array}$ & $\begin{array}{c}0 \\
(0,0)\end{array}$ & $6(18,8)$ & $\begin{array}{c}25 \\
(78,1)\end{array}$ \\
\hline $\begin{array}{l}\text { Menutup mulut dan hidung dengan menggunakan tisu saat } \\
\text { batuk/bersin, ijka tidak membawa masker }\end{array}$ & $\begin{array}{c}6 \\
(18,8)\end{array}$ & $\begin{array}{c}13 \\
(40,6)\end{array}$ & $\begin{array}{c}12 \\
(37,5)\end{array}$ & $6(18,8)$ & $\begin{array}{c}10 \\
(31,3)\end{array}$ & $\begin{array}{c}15 \\
(46,9) \\
(40)\end{array}$ \\
\hline Menutup mulut dan hidung menggunakan lengan baju bagian dalam & 15 & 10 & 6 & $8(25,0)$ & 17 & 6 \\
\hline saat batuk/bersin, jika tidak membaya masker & $(46,9)$ & $(31,3)$ & $(18,8)$ & & $(53,1)$ & $(18,8)$ \\
\hline Membuang tisu yang sudah dipakai ke tempat sampah & $\begin{array}{c}9 \\
(28,1)\end{array}$ & $\begin{array}{c}11 \\
(34,4)\end{array}$ & $\begin{array}{c}11 \\
(34,4)\end{array}$ & $\begin{array}{c}2 \\
(6,3)\end{array}$ & $\begin{array}{c}10 \\
(31,3)\end{array}$ & $\begin{array}{c}19 \\
(59,4)\end{array}$ \\
\hline $\begin{array}{l}\text { Mencuci tangan menggunakan air mengalir dan sabun setelah } \\
\text { batuk/bersin }\end{array}$ & $\begin{array}{c}12 \\
(37,5)\end{array}$ & $\begin{array}{c}10 \\
(31,3)\end{array}$ & $\begin{array}{c}9 \\
(28,1)\end{array}$ & $\begin{array}{c}0 \\
(0,0)\end{array}$ & $\begin{array}{c}14 \\
(43,8)\end{array}$ & $\begin{array}{c}17 \\
(53,1)\end{array}$ \\
\hline Membuka ventilasi setiap hari agar terjadi sirkulasi udara yang baik & $\begin{array}{c}15 \\
(46,9)\end{array}$ & $\begin{array}{c}9 \\
(28,1)\end{array}$ & $\begin{array}{c}7 \\
(21,9)\end{array}$ & $\begin{array}{c}3 \\
(9,4)\end{array}$ & $9(28,1)$ & $\begin{array}{c}19 \\
(59,4)\end{array}$ \\
\hline Menjemur peralatan tidur seperti sprei, bantal dan selimut & $\begin{array}{c}12 \\
(37,5)\end{array}$ & $\begin{array}{c}8 \\
(25)\end{array}$ & $\begin{array}{c}11 \\
(34,4)\end{array}$ & $8(25,0)$ & $5(15,6)$ & $\begin{array}{c}18 \\
(56,3)\end{array}$ \\
\hline $\begin{array}{l}\text { Menggunakan peralatan makan dan minum yang berbeda dengan } \\
\text { anggeta keluarga yang menderita TB }\end{array}$ & $\begin{array}{c}4 \\
(12,5)\end{array}$ & $\begin{array}{c}8 \\
(25)\end{array}$ & $\begin{array}{c}19 \\
(59,4)\end{array}$ & $\begin{array}{c}0 \\
(0,0)\end{array}$ & $\begin{array}{c}13 \\
(40,6)\end{array}$ & $\begin{array}{c}18 \\
(56,3)\end{array}$ \\
\hline Menghindari kontak langsung dengan penderita TB & $8(25)$ & $\begin{array}{c}5 \\
(15,6)\end{array}$ & $\begin{array}{c}18 \\
(56,3)\end{array}$ & $\begin{array}{c}0 \\
(0,0)\end{array}$ & $5(15,6)$ & $\begin{array}{c}26 \\
(81,3)\end{array}$ \\
\hline Mengkonsumsi makanan bergizi dan diolah der & $\begin{array}{c}5 \\
(15,6)\end{array}$ & $\begin{array}{c}5 \\
(15,6)\end{array}$ & $\begin{array}{c}21 \\
(65,6)\end{array}$ & $7(21,9)$ & $9(28,1)$ & 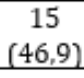 \\
\hline
\end{tabular}

Keterangan : Tidak mampu mempraktikkan (0), Mampu mempraktikkan dengan bimbingan (1), Mampu mempraktikkan dengan mandiri (2)

Sumber : Data primer yang diolah

Berdasarkan tabel 2, kemampuan responden dalam mempraktikkan upaya pengendalian dan pencegahan penularan dalam perawatan anggota keluarga dengan TB dikategorikan menjadi 3 kategori, yaitu tidak mampu mempraktikkan (skor 0), mampu mempraktikkan dengan bimbingan (skor 1) dan mampu mempraktikkan dengan mandiri (skor 2). Tabel 2 menunjukkan kemampuan responden sebelum dan setelah diberikan intervensi. Dari tabel tersebut menunjukkan terdapat peningkatan kemampuan responden dalam mempraktikkan tindakan-tindakan sebagai upaya pengendalian dan pencegahan penularan dalam perawatan anggota keluarga dengan TB setelah diberikan intervensi.

Berdasarkan tabel 3, rata-rata nilai pretest adalah

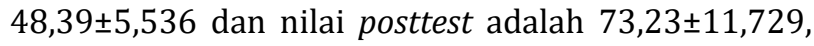
dengan nilai $p$-value sebesar 0,000 yang artinya terdapat perbedaan yang signifikan antara kemampuan responden dalam mempraktikkan upaya pengendalian dan pencegahan penularan dalam perawatan anggota keluarga dengan TB sebelum dan sesudah diberikan intervensi.

Tabel 3. Distribusi Rata-Rata Perbedaan Kemampuan Responden dalam mempraktikkan Upaya Pengendalian dan Pencegahan Penularan dalam Perawatan Anggota Keluarga dengan TB Sebelum dan Setelah Diberikan Intervensi $(n=31)$.

\begin{tabular}{lcccc}
\multicolumn{1}{c}{ Hasil } & n & Mean & SD & p value \\
\cline { 1 - 4 } Pretest & 31 & 48,39 & 5,536 & 0,000 \\
\cline { 1 - 4 } Posttest & 31 & 73,23 & 11,729 & \\
\hline
\end{tabular}

Sumber : Data primer yang diolah 


\section{PEMBAHASAN}

\section{Karakteristik Responden}

Pada penelitian ini, rerata usia responden adalah $43,17 \pm 6,690$ tahun, usia tersebut tergolong usia produktif atau usia muda. Rentang usia 18-45 tahun, merupakan usia dimana manusia sudah matang secara fisik dan biologis. Rentang usia tersebut lebih mudah dalam menerima dan mencerna informasi, semakin bertambah usia akan berpengaruh terhadap kemampuan seseorang dalam menyerap informasi. Seseorang yang berada pada usia produktif atau usia muda akan lebih matang, lebih mudah menerima dan mencerna informasi, ide dan juga pembaharuan pengetahuan dibandingkan seseorang yang berada pada usia tidak produktif $(<$ dari 18 tahun atau $>65$ tahun) (Sari, 2014).

Tinggi rendahnya tingkat pendidikan seseorang menentukan sikap dan pola perilakunya, semakin tinggi tingkat pendidikan seseorang maka makin tinggi pula tingkat pola perilakunya, namun semakin rendah tingkat pendidikan seseorang maka hampir dapat dipastikan tingkat pola perilakunya juga rendah (Sriyono, 2015). Hal tersebut sesuai dengan karakteristik responden pada penelitian ini yaitu $41,9 \%$ responden berlatar pendidikan SMP. Tingkat pendidikan tersebut menyebabkan belum optimalnya kemampuan responden dalam mempraktikkan tindakan-tindakan sebagai upaya pengendalian dan pencegahan penularan dalam perawatan anggota keluarga dengan TB sehingga diperlukan strategi yang efektif dan inovatif dengan penerapan metode MONTASE.

\section{Pengaruh MONTASE terhadap Kemampuan Praktik Responden tentang Pengendalian Dan Pencegahan Penularan Dalam Perawatan Anggota Keluarga Dengan TB}

MONTASE adalah metode pembelajaran yang diwujudkan dalam bentuk permainan, dengan menggabungkan atau memposisikan beberapa gambar yang sudah jadi untuk digunting, dilipat dan ditempelkan ditempat yang baru dan dipadupadankan dengan bentuk dari gambar yang lainnya. Metode pembelajaran ini lebih aktif, kreatif, inovatif, efektif dan menyenangkan daripada metode pembelajaran konvensional seperti ceramah dan tanya jawab.
MONTASE diterapkan melalui teknik 3M, yaitu melipat, menggunting dan menempel/merekat, proses ini merupakan proses manipulasi lembaran kertas menjadi suatu bentuk tiga dimensi (Mulyatiningsih (2017).

MONTASE efektif diterapkan baik pada anak-anak maupun dewasa sehingga dapat dilakukan bersamasama. Metode ini terbukti mempunyai daya retensi yang lebih kuat daripada metode konvensional, melalui metode ini juga mengajarkan sesuatu yang abstrak menjadi konkrit. Metode ini juga sebagai alternatif sehingga menciptakan kegiatan pembelajaran yang menyenangkan (Azizah., 2016). Metode pembelajaran MONTASE juga mampu membangkitkan daya imajinasi dan kreativitas seseorang (Dewi et al., 2015).

Penelitian ini menunjukkan bahwa metode pembelajaran MONTASE lebih efektif daripada metode konvensional. Metode pembelajaran MONTASE yang diaplikasikan dalam bentuk penerapan seni 3M yaitu melipat, menggunting dan menempelkan gambar diatas kertas yang membentuk cerita bergambar secara signifikan meningkatkan kemampuan praktik responden ( $p$ value 0,000). Hasil penelitian ini didukung oleh Mulyatiningsih (2017) bahwa metode pembelajaran MONTASE dengan menerapkan seni 3M yaitu melipat, menggunting dan menempelkan gambar diatas kertas yang membentuk cerita bergambar, yang lebih aktif, kreatif, inovatif, efektif dan menyenangkan daripada metode pembelajaran konvensional.

Metode pembelajaran konvensional hingga saat ini masih digunakan dalam proses pembelajaran, hanya saja model pembelajaran konvensional saat ini sudah mengalami berbagai perubahan-perubahan karena tuntutan zaman. Pada metode pembelajaran konvensional, peserta diposisikan sebagai objek belajar yang berperan sebagai penerima informasi secara pasif, penyampaian materi menggunakan metode ceramah dan tanya jawab, dilakukan dengan satu arah serta lebih banyak mendengarkan dan mencatat (Ibrahim., 2017). Fuad el al., (2017) juga menjelaskan bahwa metode pembelajaran MONTASE lebih menarik dan tidak membosankan sehingga dapat menumbuhkan daya imajinasi dan kreatifitas peserta serta meningkatkan keaktifan peserta. 


\section{KESIMPULAN}

MONTASE dapat meningkatkan kemampuan responden dalam mempraktikkan tindakan-tindakan sebagai upaya pengendalian dan pencegahan penularan dalam perawatan anggota keluarga dengan TB. Metode

\section{DAFTAR PUSTAKA}

Azizah, I,M. Efektivitas Pembelajaran Menggunakan Permainan MONTASE terhadap Motivasi dan Hasil Belajar di MIN Ngronggot Nganjuk. Dinamika Penelitian. 2016; Vol. 16. No. 2. p: 279-308

Dewi, I, A., Suarni, N, K., Magta, M. Penerapan Metode Proyek melalui Kegiatan 3M untuk Meningkatkan Kreativitas Anak dan Orangtua di TK Negeri Pembina. E-Journal PG PAUD Universitas Pendidikan Ganesha. 2015; Vol. 3. No. 1. p: 89-106

Fuad, Z., A., Helminsyah, Subhananto, A. Pengembangan Model Pembelajaran MONTASE Kreatif dengan Teknik Lihat, Gunting, Tempel dan Ceritakan (LGTC) untuk Meningkatkan Ketrampilan Berbicara Siswa Sekolah Dasar. Jurnal Visipena. 2017. Vol. 8. No. 2. p: 280-294

Ibrahim. Perpaduan Model Pembelajaran Aktif Konvensional (Ceramah) dengan Cooperatif (Make - A Match) untuk Meningkatkan Hasil Belajar Pendidikan Kewarganegaraan. 2017. Suara Guru: Jurnal Pendidikan Sosial, Sains dan Humaniora. 3(2), 199-212

Kemenkes RI. Petunjuk teknis manajemen dan tatalaksana TB anak. Jakarta: Kementerian Kesehatan RI; 2016 pembelajaran MONTASE dengan menerapkan seni 3M yaitu melipat, menggunting dan menempelkan gambar diatas kertas yang membentuk cerita bergambar, lebih kreatif, efektif dan menyenangkan daripada metode pembelajaran konvensional.

Kementerian Kesehatan RI. Profil Kesehatan Provinsi Daerah Istimewa Yogyakarta Tahun 2016. Yogyakarta; 2017

Kemenkes RI. Tuberkulosis. InfoDATIN. Pusat Data dan Informasi Kementerian Kesehatan RI. Jakarta; 2018

Sari, D. 2014. Hubungan Tingkat Pengetahuan, Sikap dengan Perilaku Ibu dalam Stimulasi Perkembangan Anak Usia 0-12 Bulan di Puskesmas Mergangsan Kota Yogyakarta. Skripsi. STIKES Aisyiyah Yogyakarta

Sriyono. 2015. Pengaruh Tingkat Pendidikan dan Pemahaman Masyarakat tentang Ikan Berformalin terhadap Kesehatan Masyarakat. Faktor Exacta. 8(1). 79-91

Widiastuti, R. Peran Keluarga dalam Merawat Anggota Keluarga yang Menderita Tuberkulosis Paru di Wilayah Kerja Puskesmas Wirobrajan Yogyakarta. Skripsi. Program Studi Ilmu Keperawatan Universitas Aisyiyah Yogyakarta; 2019

World Health Organisation (WHO). Current Status of Integrated Community Based TB Service Delivery and The Global Fund Work Plan to Find Missing TB Cases; 2018 